\title{
What is the Normativity of Meaning?
}

\section{Daniel Whiting}

The definitive version of this article is to be published in Inquiry, and will be available here: http://www.tandfonline.com/loi/sinq20. Please refer to the published version.

\begin{abstract}
There has been much debate over whether to accept the claim that meaning is normative. One obstacle to making progress in that debate is that it is not always clear what the claim amounts to. In this paper, I try to resolve a dispute between those who advance the claim concerning how it should be understood. More specifically, I critically examine two competing conceptions of the normativity of meaning, rejecting one and defending the other. Though the paper aims to settle a dispute among proponents of the claim that meaning is normative, it should be of interest to those who challenge it. After all, before one takes aim, one's target needs to be in clear view.
\end{abstract}

\section{Key words}

meaning; normativity; truth; assertion; language 


\section{What is the Normativity of Meaning?*}

\section{$1 \quad$ Introduction}

'Meaning is normative.' ${ }^{1}$ For some time now, philosophers have been circulating slogans like this. It is perhaps Kripke, in his influential (and controversial) reading of Wittgenstein's remarks on rule-following (1982), who is most responsible for the present popularity of such slogans. On behalf of Wittgenstein, or 'Wittgenstein as his thought struck Kripke', Kripke writes:

Suppose I do mean addition by ' + '. What is the relation of this supposition to the question how I will respond to the problem ' $65+57$ '? The dispositionalist gives a descriptive account of this relation: if ' + ' meant addition, then I will answer ' 125 '.

But this is not the proper account of the relation, which is normative, not descriptive.

The point is not that, if I meant addition by ' + ', I will answer ' 125 ', but that, if I intend to accord with my past meaning of ' + ', then I should answer ' 125 '. (1982: 37)

The general consensus among scholars is that Kripke's reading of Wittgenstein is a misreading in almost all respects with one notable exception - the point about the 'relation' of meaning to use being a normative one. Commentators as otherwise diverse as Bloor (1997), Brandom (1994), Buleandra (2008), Glendinning (1998), Glock (2005), Hacker (2010), Lance and Hawthorne (1997: 180ff), Luntley (2003), McCulloch (1995), McDowell (1998), McGinn (1984), Railton (2001), Schroeder (2006: 174), Stone (1999), Stroud (2000: 186-187), Thornton (1998), Weiss (2010:

\footnotetext{
* This paper has been a long time in development and has survived through several changes of mind. Thanks to all those whose input helped to shape it, including Maria Alvarez, Jeff Speaks, Indrek Reiland, Jussi Suikannen, Jonathan Way, anonymous referees, and audiences at the University of East Anglia and Lund University.

${ }^{1}$ I shall focus exclusively upon linguistic meaning, the meanings which expressions possess in a language, whether the public language or a person's idiolect. Some philosophers advance similar slogans with respect to mental content. I shall not comment on this issue, though presumably much of what follows bears on it.

Note that, in the passage below and throughout his discussion, Kripke's focus shifts between what a speaker means in using an expression and what her word means in the language.
} 
81), and Wright (2001) attribute to Wittgenstein the view that meaning is in some sense (constitutively, or essentially, or irreducibly, or...) normative. ${ }^{2}$ They also (without exception) endorse some version of that view, as do numerous other philosophers more or less sympathetic to Wittgenstein's philosophy, including Alston (2000), Blackburn (1984), Gibbard (1994), Ginsborg (2012), Haddock (2012), Korsgaard (1996: 20), Millar (2004), Morris (1992), Putnam (1991: 11ff), Sellars (1962), and, until recently, Boghossian (2008: ch. 1; cp. ch. 4). ${ }^{3}$

Many of the above take the slogan 'Meaning is Normative' to capture something important about meaning, something which imposes constraints upon adequate accounts of meaning, perhaps something which immediately and in advance of the details rules out certain ways of trying to capture or characterise the phenomenon altogether, in particular those ways that avail themselves only of the explanatory resources available to the natural sciences. Others take the putative insight the slogan expresses to have anti-realist or radically sceptical consequences (see Kripke 1982; Wright 2001).

Whatever its pedigree, and however popular and suggestive it might seem, a slogan it remains. As Hattiangadi notes, while the phrase is 'catchy', 'it is not always clear what it means' $(2007: 37)$. The aim of this paper is try to get clear about how it should be understood. I shall start by outlining the orthodox interpretation of the slogan. Having done so, I shall introduce a series of examples of a sort which several philosophers claim shows the orthodox interpretation to be unsatisfactory. The same philosophers suggest an alternative, unorthodox interpretation of the slogan. I shall

\footnotetext{
${ }^{2}$ Are they right to do so? Regarding the view that what an expression means is determined by what causes its use and/or the effects of its use, Wittgenstein remarks, 'the meaning of a sign is the effect which it should have [...] but not the effect that it will have' (2003: 343).

${ }^{3}$ In a similar fashion, Hanfling (2002: 6) and Mulhall (2003) attribute to Wittgenstein, and endorse, the view that language or language use is in some sense normative. This is an important theme in the work of Cavell, who writes, 'what is normative is exactly ordinary use itself' (2002: 21).
} 
examine various ways of trying to spell out that unorthodox interpretation and argue that none is satisfactory. Finally, I return to the cases which seemed to cast doubt on the orthodox reading and suggest ways in which its proponent can account for them. Defending orthodoxy is not a glamorous job, but someone's got to do it!

While this paper addresses a debate between proponents of the slogan, its results should be of interest to those who are suspicious of it. In order to evaluate critically the thought which the slogan expresses, one needs to know what that thought is.

\section{Orthodoxy}

Call the thesis to which the slogan 'Meaning is normative' gestures, Normativism, and its advocates, Normativists. Normativists do not think that what an expression means has normative import merely in the light of other considerations — say, moral, legal, aesthetic, instrumental or prudential—but that meaning is essentially normative. Accordingly, one might understand Normativism as the thesis that, from the fact that an expression bears a certain meaning, certain normative implications immediately follow. ${ }^{4}$

A widespread route to the orthodox interpretation of Normativism is via the observation that, given what an expression means, there are correct and incorrect ways of using it (see Blackburn 1984: 281; Boghossian 2008: 15; McDowell 2009: essay 11). For example, the following appears trivial (where $S$ names a subject):

(CORRECT) For any $S, x$ : if 'red' means $r e d$, it is correct for $S$ to apply 'red' to $x$ if and only if $x$ is red.

\footnotetext{
${ }^{4}$ Glüer and Wikforss (2009) call this 'meaning-engendered normativity', as opposed to 'meaningdetermining normativity'. I shall focus exclusively on the former.
} 
Of course, (CORRECT) concerns only the term 'red' but it is straightforward enough to

see how one could arrive at a generalised version of the principle that holds of other

terms. $^{5}$

All parties, even the staunchest critics of Normativism, would agree that

(CORRECT) is platitudinous. Hattiangadi, for example, states unequivocally that it is

not 'open to us to deny that in order to have meaning, terms must have correctness

conditions. This is what distinguishes the use of language from the making of mere

noise' (2006: 222). The more contentious claim is that one should understand

\footnotetext{
${ }^{5}$ There are concerns one might have about (CORRECT). Since this principle is not what is at issue in the debate this paper seeks to contribute to - all parties accept it-I shall relegate to this note a brief discussion of some of those concerns.

One might worry about the 'disquotational' character of the specification of the meaning of 'red' embedded in (CORRECT). One way to alleviate this worry might be to imagine a context in which a person is under the mistaken impression that 'red' as used by a certain person is not the familiar English word and, so as to set her straight, she is told that 'red' mean red (i.e. really is the familiar English word). However, if the worry persists, one could simply choose a different example. Nothing in what follows hangs on it.

Next, note that 'red' (in English) is ambiguous-it can mean red or, for example, communist. If 'red' means communist when I use it on a given occasion, it is not correct for me to apply it to a red balloon. (CORRECT), one might think, suggests otherwise. In response, one might appeal to the fact that context typically disambiguates an expression. The fact that the conversation concerns our favourite colour, say, and not our political allegiances determines that, on this occasion, 'red' means red, not communist. In view of this, one might reformulate the antecedent of (CORRECT) as follows: If 'red' means $r e d$ in the context of utterance.... A different response would be to say that what appears to be an ambiguous word is in fact the 'surface forms of distinct words' (cf. Segal 2006: 209), namely, 'red ${ }_{1}$ ', meaning red, and 'red ${ }_{2}$ ', meaning communist, which are unambiguous. In view of this, one might reformulate the antecedent of (CORRECT) as follows: If ' $\operatorname{red}_{1}$ ' means red.... For ease of presentation, I shall stick to the original formulation.

One might instead worry that the idea that there are specifiable general principles like (CORRECT) governing the use of expressions is at odds with the thesis of contextualism or occasionsensitivity. For critical discussion, see Whiting 2010.

Finally, one might instead worry that (CORRECT) concerns only the application of expressions (cf. Buleandra 2008). Lying behind this worry might be one of several others. First, there are words which cannot be said to apply to things - for example, 'hello', 'in', and 'sometimes' - but which nonetheless are meaningful and (so) can be employed correctly or incorrectly. However, (CORRECT) is entirely consistent with this point-it purports to capture only one respect in which meaningful expressions of a certain sort have conditions of correct use.

Second, there are words which can be said to apply but which can be used correctly or incorrectly in ways which do not involving applying them-for example, in exclamations, orders, inferences, questions, and so on. However, (CORRECT) purports to capture only one normative implication of the fact that 'red' means red; it is consistent with it that there are other such implications. Finally, one might think that certain kinds of words have the superficial appearance of being words which are used to apply to things but in fact are not—a standard example might be 'good'. Such words nonetheless have conditions of correct use. One response to this is to insist that there is no harm in saying for certain purposes that such terms are applied to things, any more than there is harm in saying that they can be used to state truths, so long as one recognises that what one is doing in 'applying' one kind of word differs from what one is doing in applying another kind of word.
} 
(CORRECT) as capturing a normative implication of the fact that 'red' means red, that correctness should be understood in this context as a normative notion.

To bring out the disputed normative reading of (CORRECT), one might reformulate it as: ${ }^{6}$

(OUGHT) For any $S, x$ : if 'red' means red, $S$ ought not to (apply 'red' to $x$ ) if and only if $x$ is not red.

I take (OUGHT) to be equivalent to:

(MAY) For any $S, x$ : if 'red' means red, $S$ may (apply 'red' to $x$ ) if and only if $x$ is red.

It is fair to say that Normativism is typically understood along something like these lines, as the thesis that (OUGHT) and (MAY) specify truths which follow immediately from facts about the condition for the correct use of the relevant expression, in this case 'red', which in turn is a consequence of its meaning what it does.

Evidently, these principles are to be understood as expressing pro tanto judgements. If applying a word which means red to a blue object is the only way to save one's children's lives, one should do so! What (OUGHT) claims is that, given only the fact that 'red' means red, one ought not to apply it to something which is blue, which is consistent with the possibility that, given all the facts, one may apply 'red' to something which is blue.

Importantly, on the version of Normativism just introduced, the relevant kind of norm which is supposed to hold in light of what an expression means is a norm of truth. ${ }^{7}$ To appreciate this, note that (OUGHT) is equivalent to:

Alternatively, one could simply restrict (CORRECT) to those expressions which can be said to apply and tell another story about other kinds of expressions.

${ }^{6}$ The brackets here indicate the scope of 'ought'.

${ }^{7}$ Alternatively, one might view 'correct' as expressing a notion like epistemic justification. For critical discussion, see Whiting 2009b. 
(TRUE) For any $S, x$ : if 'red' means red, $S$ ought not to (apply 'red' to

$x$ ) if and only if it is not true that $x$ is red.

Correct application coincides with true application. One upshot of characterising

Normativism in this way is to treat it as one with the thesis that there is a norm governing assertion, specifically, a norm of truth. On such a view, facts like the following hold quite generally: ${ }^{8}$

(ASSERT) For any $S, x: S$ ought not to (assert that $x$ is red) if and only if it is not true that $x$ is red.

The link between (OUGHT) and (ASSERT) is not immediate, since (ASSERT) does not mention applying an expression bearing a particular meaning. Nonetheless, it is straightforward enough to forge a link once one recalls that, by applying an expression that means red to an object, one is asserting of that object that it is red ${ }^{9}$ and, conversely, that asserting that an object is red requires applying a word that means red to it.

Treating the claim that meaning is normative as one with the claim that assertion is normative is widespread among Normativists. Consider the following remarks by Thornton:

Linguistic meaning has a normative dimension in that words can be used correctly or incorrectly. For any particular use of a word that has a meaning, it can be asked whether it has been used correctly or not. It can be asked whether it has been used in accordance with its meaning.

\footnotetext{
${ }^{8}$ Whether or not truth provides the normative standard for assertion is a contentious issue, exploring which is beyond the scope of this paper. For present purposes, I shall take (ASSERT) for granted and consider its implications for the debate concerning Normativism. Note that if - to consider the most prominent position in the recent literature-assertion is subject to a norm of knowledge (see Williamson 2000: ch. 11), this would generate a subsidiary norm of truth. For discussion and defence of (ASSERT), see Whiting 2013.

${ }^{9}$ Could one apply 'red' to an object without asserting that it is red, say, when supposing that it is red? I think it is more accurate to say that, when formulating a supposition, one is not applying the relevant expression but as if applying it, that is, supposing that it applies. Nothing hangs on this in what follows.
} 
In spelling out this point, Thornton informs us that the relevant normative relation concerns 'the connection between an assertion $[\ldots]$ and the state of affairs that determines whether it is true or false', which in turn raises the question, 'How does a judgement normatively prescribe or determine some state of affairs?' (1988: 32-33)

In a similar fashion, Brandom begins by stating, 'Meanings are invoked to explain how it is correct or appropriate to use words and sentences, how one ought to deploy them'. Immediately afterwards, Brandom tells us that the relevant 'linguistic propriety' governing an expression concerns 'when its assertional use is appropriate or allowable, when a speaker is licensed or entitled to use the sentence to perform that speech act' (2000: 185-6). McDowell also introduces the Normativist thought that 'the very idea' of meaning is 'fraught with "ought"'. In cashing out this pregnant remark, McDowell explains that it reflects the fact that we understand an expression's meaning as 'determining the conditions under which whole sentences are correctly or incorrectly asserted' (2009: 59-61).

Clearly, then, a widespread way of interpreting Normativism, motivated in part by the platitude that meaningful expressions have conditions of correct application, is as committed to the claim that facts about what expressions mean entail facts about how they should or may be applied, which in turn is understood as tantamount to the claim that there are facts about when subjects should or may perform speech acts of asserting, according to whether or not what would thereby be asserted is true.

Many challenge the view that there is a norm of truth of the sort captured by a generalised version of (OUGHT), one which can be seen to govern the use of meaningful language independently of, say, moral or instrumental considerations, and to the suggestion that the platitudinous status of (CORRECT) provides any support for 
such a view (see, e.g., Hattiangadi 2007). I have tried to meet these challenges elsewhere and they are not my present concern. ${ }^{10}$ Rather, I shall address a challenge to the slogan, understood in the orthodox fashion, which comes from within the Normativist camp.

\section{An unorthodox view}

I have outlined the orthodox interpretation of Normativism, according to which the fact that an expression has a certain meaning implies that there are standards for its correct and incorrect application, and so for how it should or may be used in assertion, where correctness and incorrectness coincide with truth and falsity respectively. A minority of Normativists reject this as a satisfactory interpretation of the thought to which the slogan 'Meaning is normative' points and suggest an alternative, including Millar (2004: ch. 6), Glock (2005), McGinn (1984), and Schroeder (2008). ${ }^{11}$ Another name to add to the list is Moore who, in reporting Wittgenstein's lectures, advances the following line of thought:

From the fact that you are using language correctly, in the sense of 'in accordance with an established rule', it by no means follows that what you assert, by this correct use of language, is 'correct' in the very different sense in which 'This is correct' = 'This is true', nor from the fact that you are using language incorrectly that what you assert by this incorrect use is 'incorrect' in the very different sense in which 'That is incorrect' $=$ 'That is false'. (1954: 308-309)

With Moore, proponents of the unorthodox interpretation of the slogan 'Meaning is normative' draw a distinction between what one might call semantic correctness/incorrectness and factual correctness/incorrectness. As Glock puts it, 'one

\footnotetext{
${ }^{10}$ For an overview of such objections and attempts to meet them, see Whiting 2009a. For a recent and interesting objection which, to my knowledge, has yet to receive critical attention, see Speaks 2009.
} 
can apply a word in a way which is semantically correct, without applying it correctly in the sense of applying it to say something true', and vice versa (2005: 229). ${ }^{12}$

Truly or falsely applying an expression - and so correctly or incorrectly asserting — is one thing, using a term in a way which is semantically correct - in keeping with its meaning - is quite another. Correctly using an expression in the one sense can diverge from correctly using it in the other sense. The proponents of the orthodox reading allegedly overlook this distinction and so conflate the two sorts of correctness.

To appreciate this, consider examples of the sort Glock (2005), Millar (2004), and Schroeder (2008) discuss. Suppose that Mike applies 'vixen' to a female fox, taking the creature to be a male cat. It appears that Mike makes a true statementtruly applies 'vixen' - and so makes no factual error. However, there appears to be a semantic error-Mike's use of 'vixen' seems not to accord with its meaning. He uses it as if it means something other than it does, as if it applies to a creature on the basis of its being a male cat.

Suppose now that Sophie applies 'vixen' to a female fox, and does so thinking that the creature is a female fox. It seems that Sophie makes a true statement-truly applies 'vixen' — and so makes no factual error. Moreover, there appears to be no

\footnotetext{
${ }^{11}$ See also Buleandra 2008; Miller Forthcoming. I should add that Schroeder is officially exploring, not endorsing, an alternative conception of semantic normativity.

${ }^{12}$ I shall focus in what follows on one influential unorthodox account of the normativity of meaning; there are others, which I do not have space to discuss here. According to Ginsborg $(2011 ; 2012)$, for example, the normativity of meaning concerns a subject's using an expression in 'awareness that what she is doing is appropriate', where being appropriate is a matter neither of how she ought, in the reasons-implying sense, to use the expression nor of how it correctly, in the sense of truly, applies (cf. 2012: 138). For a critical discussion of Ginsborg's view, see Haddock 2012.

One finds further unorthodox accounts in the work of Gampel (1997) and Verheggen (2011). Although they differ in the details of their views and in what they take the consequences of those views to be, both argue that meaning is 'essentially' normative and at the same time insist that the normativity in question is, in Gampel's words, 'only hypothetical, not categorical, depending for its force on the aims of the agent and on other normative pressures' (2012: 228). Exploring views of this sort is the task for another occasion.
} 
semantic error-Sophie's use of 'vixen' accords with its meaning what it does in a way that Mike's does not.

Suppose finally that Bekki applies 'vixen' to a male cat. Nonetheless, Bekki takes the creature to be a female fox. It appears that Bekki makes a false statementfalsely applies 'vixen' — and so makes a factual mistake. However, there appears to be no semantic error-Bekki's use of 'vixen', like Sophie's, accords with its meaning what it does.

These examples (appear) to point to a distinction between using an expression correctly by truly applying it and using it correctly by according with its meaning, and so to a distinction between the normative considerations that obtain as a result of the fact that one is performing the speech act of assertion and those that obtain given only what one's words mean. The unorthodox Normativists complain that the orthodox overlook this distinction.

It is worth stressing at this point that the unorthodox Normativists are not merely complaining that there is more to the normativity of meaning than (CORRECT) and its kin express, that those principles capture only some of the normative considerations which hold in light of the fact that an expression bears a certain meaning (cf. n5 above); rather, they claim that what the orthodox present as the normativity of meaning is in fact no such thing; at best, it captures the normativity of assertion.

While the idea that there is a distinction between factual and semantic correctness has some intuitive appeal, the difficulty is how to articulate that distinction, in particular, how to spell out the notion of according with meaning.

\section{$4 \quad$ According with meaning}


Consider first the following characterisation of semantic correctness by McGinn. Correctness in the sense of according with an expression's meaning is 'a matter of meaning now what one meant earlier' (1984: 174). This suggests a generalised version of the following (where ' $t 1$ ' gives a time and ' $t 2$ ' a later time):

$\left(\mathrm{ACCORD}_{1}\right) \quad$ For any $S$ : if $S$ means red by 'red' at $t 1$, then $S$ ought to (mean red by 'red' at $t 2$ ).

An initial worry with $\left(\mathrm{ACCORD}_{1}\right)$ is that, as formulated, it is a principle concerning speaker meaning rather than linguistic meaning, which suggests that it will be of little use in elucidating a notion of linguistic correctness and will have no immediate bearing on theories of linguistic meaning. Setting this aside, another problem is that meaning something at a certain time by an expression different than what one meant by it on an earlier occasion just does not look like a mistake. As Wikforss puts the point, "If at $t 2$ I use "horse" with a different meaning than at $t 1$, then I have simply changed my intentions and the word has a different meaning' (2001:210).

Furthermore, it is just implausible to suggest that what a subject means by an expression on a particular occasion on its own gives her any reason to mean the same thing by it on a future occasion. Of course, there might in certain circumstances be reasons not to change what one means by one's words-for the sake of smooth communicative exchange perhaps_-but such reasons would precisely not be a consequence of what those words mean alone.

Elsewhere, McGinn characterises semantic incorrectness as a matter of 'using the same word with a different meaning from that originally intended (and doing so in ignorance of this change)' (1984: 147). This suggests another version of Normativism, according to which the following principle holds: 
$\left(\mathrm{ACCORD}_{2}\right) \quad$ For any $S$ : if $S$ intends at $t 1$ to mean red by 'red' at $t 2$, then $S$ ought to (mean red by 'red' at $t 2$ ).

Setting aside the fact that $\left(\mathrm{ACCORD}_{2}\right)$ also concerns speaker meaning, the problem with it is that it does not seem to capture a distinctive kind of semantic normativity. Granting that $\left(\mathrm{ACCORD}_{2}\right)$ expresses a truth, the relevant normative statement follows from a subject's having a certain intention; thus, it looks like it expresses a species of instrumental normativity, concerning what one should do to fulfil one's intentions. A mistake, on this view, is failing to accord with one's (prior) intentions, rather than failing to accord with meaning. Whether or not there is such a species of normativity, that is, whether or not the fact that one has a certain intention has any normative import, $\left(\mathrm{ACCORD}_{2}\right)$ cannot provide Normativists with an articulation of the thesis they seek to advance; it might have implications for theories of intention, but not for theories of meaning.

McGinn might reply that what is incorrect in the distinctively semantic sense is going against one's intentions unwittingly. Perhaps one means blue by 'red' at $t 2$ because one wrongly takes this to satisfy what one intended at $t 1$, namely, to mean red by 'red' at $t 2$. However, if there is a mistake here, it is a mistake of judgementone judges that such-and-such accords with one's previous intention, when in fact it does not. The judgement is incorrect to the extent that it is untrue. This proposal is in danger of collapsing into the view that there is a norm according to which true judgement is correct and false judgement is incorrect, which the orthodox Normativist could accept.

All of this suggests that McGinn's attempts to characterise a distinctive form of semantic normativity in terms of what a subject means by an expression on different occasions is unsuccessful. As Boghossian insists, though his route to this 
conclusion is different from that taken here, the normativity of meaning does not concern 'a relation between meaning something by an expression at one time and meaning something by it at some later time' but rather 'a relation between meaning something by it at some time and its use at that time' (2008: 15). And, I would add, it does not concern what an expression should mean, or what someone should mean by it, but how a subject should use an expression given what it does mean.

Millar tells us that semantic, as opposed to factual, incorrectness results when there is a 'mismatch between what I say when I apply the term, and what I mean to say when applying it'. He continues:

When we make statements we give it to be understood that what we say is true and that we said what we meant to say. This dictates that the words we use when we state something to be so should be apt to say what we mean to say. $(2004: 163 \text {; cf. } 177)^{13}$ One might try to capture the thought here, with respect to the use of 'red', as follows:

$\left(\mathrm{ACCORD}_{3}\right) \quad$ For any $S, x$ : if $S$ intends to express the thought that $x$ is red, then $S$ ought to (apply 'red' to $x$ if and only if 'red' means red). Unfortunately, $\left(\mathrm{ACCORD}_{3}\right)$ reintroduces a familiar difficulty. It no longer appears that what Millar draws attention to is a species of distinctively semantic normativity, since the relevant normative statement about what the subject ought to do is a consequence of the fact that she intends to express a certain thought, rather than the fact that the expression means what it does. Thus, like $\left.\left(\mathrm{ACCORD}_{2}\right),(\mathrm{ACCORD})_{3}\right)$ concerns a species of instrumental normativity. This is not what the Normativist is after.

Elsewhere, Millar offers a quite different way to characterise a supposedly distinctive kind of semantic correctness:

\footnotetext{
${ }^{13}$ Here Millar characterises the relevant normative considerations in terms of how one 'should' use words; elsewhere, he recommends characterising them in terms of how one is 'committed' to using words. There is not space to address the issue of whether one should understand the normativity of
} 
A use is correct in the sense of being in keeping with the relevant meaning provided that it is not a misuse. It is a misuse when it fails to respect the conditions of correct (= true) application of the term. $(2004: 165)$

Again, Millar seems not to succeed in articulating the relevant notion of semantically correct use. What exactly does it mean, one might ask, to respect the conditions of correct application for a term, but to use it in a way that accords with those conditions, namely, by correctly (=truly) applying it? That is, what is to respect the conditions of correct application if it is not to (try to) satisfy them? Millar has yet to capture a notion of 'correctness of use, conceived as use in keeping with meaning' that diverge from 'correctness of use, conceived as true application' (2004: 165).

Consider now Moore's comments on the alleged distinction between two kinds of correctness:

It by no means follows, for instance, from the fact that you are using the word 'foot' 'correctly', i.e. for the length for which it is usually used in English, that when you make such an assertion as 'This rod is less than four feet long', your assertion is true; and, if you were to use it 'incorrectly' for the length which is properly called in English an 'inch' or for that which is properly called a 'yard', it would by no means follow that any assertion you made by this incorrect use of the word 'foot' was false. (1954: 309)

A semantic mistake, on this view, is using a word to signify ('for') something which the word in English (or whatever) does not signify.

However, if I use a word which in English signifies the colour red to signify or speak of the colour blue, it hardly follows that I have made a mistake-perhaps I am speaking some variant of English, or have introduced a linguistic innovation, or am

meaning as a matter of 'should's (and 'ought's) or of 'commitment's (in Millar's sense), and the issue does not bear immediately on the present discussion. 
speaking a different language. Of course, if I am intending to speak ('proper')

English, then I am making a mistake insofar as I am failing to execute my intention.

But any norm which would deliver the verdict that such a mistake has been made

would, once more, be instrumental. Alternatively, if I judge that 'red' (in English) is a

word for the colour blue, then I am making a mistaken judgement. But this is to return

to the view which we looked to Moore for an alternative to, according to which 'This

is incorrect' $=$ 'This is false'. Perhaps there are views according to which there is

some reason, at least for some people, to speak ('proper') English (as opposed to

some other language); but, whatever that reason is, it is surely not going to be

provided by nothing more than the fact that the words in English mean what they do. ${ }^{14}$

Despite all the twists and turns, a satisfactory alternative interpretation of the

slogan, 'Meaning is normative', remains outstanding. To be sure, in applying the term

'red', there are things one might do which one should not do other than falsely

asserting that an object is red, like judging that 'red' means blue or acting so as to

frustrate one's intention. But the search was for a kind of correctness which diverges

from factual correctness or for a species of normativity other than instrumental. ${ }^{15}$

Perhaps the following captures what the proponent of the unorthodox

conception of the normativity of meaning has in mind:

\footnotetext{
${ }^{14}$ One might wonder why I have yet to consider the appeal to the notion of a practice, which figures prominently in Millar's discussion and which has considerable Wittgensteinian pedigree. Perhaps one could use that notion to characterise a way in which the use of an expression might be correct without being used to express a truth or incorrect without being used to express a falsehood. Using an expression correctly in the relevant sense is using it in a way that accords with practice, while using it incorrectly in the relevant sense is using it a way that fails to accord with practice.

I do not think this gets us very far. What is the practice of using the (English) word 'red' if not the practice of applying it to red things? One might suggest (following Moore) that the practice is one of using the word 'red' to signify the colour red, in which case using the word incorrectly, in the relevant sense, is using it to signify something other than red. But it is hard to see how a person who uses the word 'red' for, say, the colour blue can be said to be participating in the practice of using the word 'red' to signify the colour red at all-indeed, she precisely seems not to be participating in that practice. Of course, she might be intending to do so, or she might think that she is, but this raises now familiar issues.
} 
$\left(\mathrm{ACCORD}_{4}\right) \quad$ For any $S, x$ : if 'red' means red, $S$ may (apply 'red' to $x$ ) if and only if $S$ believes that $x$ is red.

Schroeder suggests this principle. He writes, for example, that a 'sentence means that $p$ because that is the belief that it is only correct to assert the sentence if you have' (2008: 109). And, at one point, McGinn says that correct use in the relevant sense is a matter of 'which word is linguistically appropriate to the facts'. To illustrate, he offers the following example:

Suppose I truly believe that this object is red; the question of linguistic correctness is then which word expresses this belief: is 'red' the word I ought to use to state the fact in which I believe? (1984: 60)

A generalised version of $\left(\mathrm{ACCORD}_{4}\right)$ would certainly deliver verdicts concerning the cases involving 'vixen' above which diverge from those which (OUGHT) and the like deliver. Moreover, since it makes no reference to intentions, whatever normativity $\left(\mathrm{ACCORD}_{4}\right)$ concerns, it would appear not to be instrumental. This is looking promising.

\section{$5 \quad$ In defence of orthodoxy}

In the remainder, I shall challenge this unorthodox account of the normativity of meaning. In the first instance, I shall argue that reflection on the kinds of cases outlined in $\S 3$ does not support the rejection of (OUGHT) and the like in favour of $\left(\mathrm{ACCORD}_{4}\right)$. To do so, I shall develop a familiar analogy in the service of an unfamiliar point.

According to what one might call the orthodox view of chess, moves in the game are governed by rules, including one which states that one should not move a

\footnotetext{
${ }^{15}$ As noted above (n5), there might also be norms governing how a word is to be used in, say, inference. But such norms would be additional to, rather than an alternative to, the sort expressed by (CORRECT)
} 
piece diagonally if it is a rook. Suppose that Harry is playing chess. Due to some dust in his eye, Harry mistakes a rook for a bishop and moves the piece diagonally. Now suppose that Holly is playing chess. Holly moves a rook horizontally having mistaken it for a bishop.

Harry's and Holly's situation are analogous in the relevant respects to Bekki's and Mike's. But presumably one should not arrive, by parity of reasoning, at an unorthodox view of chess, according to which the use of a rook is actually governed by a rule according to which one should not move a piece diagonally if one believes that it is a rook. That would certainly conflict with what the rule book says! ${ }^{16}$

Surely the thing to say is that Harry violates the chess rule and Holly does not. Since Harry's violation is due to a mistaken belief, a factual error, one might say that it is blameless or reasonable (assuming his error in belief was blameless or reasonable). In contrast, though Holly conformed to the rule of chess, she might be criticisable, given that she believes the piece to be a bishop. That said, the case of Holly is underdescribed. Perhaps she believes (wrongly but reasonably) that, according to the rules of chess, one may move a bishop horizontally. In that case, her move might be blameless or reasonable.

What this shows is that numerous mistakes or error might be involved in rulegoverned activities like chess. First, one might violate the relevant norm, e.g. by moving a bishop horizontally. Second, one might make a mistaken factual judgement about the world, e.g. that a certain piece is a rook. Third, one might make a factual mistake about what the norm is or what it requires, e.g. that one may move a bishop

and its variants.

${ }^{16}$ According to the handbook of the World Chess Federation, the following is a 'law of chess': the rook may move to any square along the file or the rank on which it stands. The rule is not: what one believes to be the rook may move to any square along the file or the rank on which it stands. See: http://www.fide.com/component/handbook/?id=124\&view=article [accessed 14/03/2013]. 
horizontally. In some cases, the first kind of mistake might be the result of one of the other kinds.

All of this is consistent with, indeed vindicates, the orthodox view of chess. The only relevant rule of chess in the cases that concern us is: one should not move a piece diagonally if it is a rook. Failure to accord with this rule might be due to a mistaken belief about what the rule is, or about whether it applies in a given instance. Of course, belief itself might be governed by a norm which delivers the verdict that a mistake has been made - perhaps a norm according to which one may believe that $p$ only if $p$-but this is clearly not a norm of chess.

Returning in light of all of this to cases like those involving Mike and Bekki, parity of reasoning suggests the following. Numerous mistakes or error might be involved in the norm-governed use of language. First, one might violate the relevant norm, e.g. by applying 'vixen' to a male cat. Second, one might make a mistaken factual judgement about the world, e.g. that something is a female fox. Third, one might make a factual mistake about what the norm is or what it requires, e.g. that one may apply 'vixen' to a male cat. In some cases, the first kind of mistake might be the result of one of the other kinds.

All of this is consistent with, indeed vindicates, orthodox Normativism. The only relevant rule in the cases that concern us is: one should not apply 'vixen' to something unless it is a female fox. Failure to accord with this rule might be due to a mistaken belief about what the rule is, or about whether it applies in a given instance. Of course, such belief might be governed by a norm by reference to which one judges that a mistake has been made-perhaps a norm according to which one may believe that $p$ only if $p$-but this is clearly not a norm of language. So, reflection on the cases above does not give us reason to reject orthodox Normativism. 


\section{The defence continued}

In this section, I shall make some additional points in support of orthodoxy regarding the normativity of meaning and in criticism of the unorthodox view under consideration.

It is common for those rejecting orthodoxy to appeal to the thought that a subject who misapplies an expression, and hence asserts a falsehood, is not making a semantic mistake but a mistake about the world or the language-independent facts (see, e.g., Schroeder 2008: 108-109). That is right. But it does not follow that such a speaker is not thereby violating a semantic norm.

It is natural to think that, just as a geographical, historical, or mathematical mistake is a mistake about some geographical, historical, or mathematical matter, a semantic mistake is a mistake about semantics, that is, a mistake about what a word means (or about the norms governing its use). As we have seen, such a mistake is a species of factual mistake, involving a mistaken belief or judgement, and might explain why a subject violates a semantic norm. In a parallel fashion, a mistake about the rules of chess is a species of factual mistake, involving a mistaken belief or judgement, and might explain why a subject violates a rule of chess. Whether a subject makes a semantic mistake and whether she accords with a semantic rule look like two separate matters.

One might wonder why, if failure to accord with a semantic norm need not involve or amount to a semantic mistake, we nonetheless describe the norm as semantic (as opposed to, say, assertoric or alethic). The (orthodox) Normativist answer is that the fact that the relevant norm governs the use of the expression is 
essential to its meaning what it does, that is, to its having the semantic properties that it does; it is because of this connection that the norm counts a semantic.

These points in turn cast doubt on the common suggestion that a violation of a semantic norm betokens a lack of understanding or inadequate grasp of the meaning of an expression (see, e.g., Glock 2005: 229). Since misapplying (=falsely) an expression need not betoken lack of understanding, this is supposed to show that misapplying an expression is not a violation of a semantic norm.

It is certainly plausible to think that a semantic mistake evinces a poor understanding or grasp of an expression's meaning. But, as we have just seen, whether a subject makes a semantic mistake is a different issue to whether she accords with a semantic norm. Compare: when someone moves a rook diagonally, does this betoken lack of understanding (of chess)? It may or may not do so, depending on whether the mistake was due to a mistaken judgement about what the rules require. Either way, the rules require her not to move a rook diagonally.

\section{$7 \quad$ A can of worms}

So far, I have argued that the case against orthodoxy is unsuccessful. In this penultimate section, I shall tentatively suggest that, even if the proponent of the orthodox interpretation of the slogan, 'Meaning is normative', is forced to accept $\left(\mathrm{ACCORD}_{4}\right)$, she might account for it in a manner which is consistent with that interpretation. The remarks to follow introduce some somewhat controversial ideas which I cannot adequately defend here. Fortunately, the preceding arguments do not depend on them.

It is common for philosophers not participating in the debate over the normativity of meaning to distinguish between what one objectively ought to do and 
what one subjectively ought to do (see Parfit 2010: ch. 1; Schroeder 2007; Way 2009). Very roughly, objective norms tell us what to do given the facts, while subjective norms tell us what to do given our beliefs about the facts. ${ }^{17}$ Objective norms are basic or fundamental, on this view, while subjective norms are derived from and explained in terms of them, as follows. One subjectively ought to $\varphi$ in a situation just in case, were one's beliefs about the situation true, it would be the case that one objectively ought to $\varphi$. In this way, the objective norm is more basic in the order of explanation; what one subjectively ought to do is explained in terms of what one objectively ought to do in counterfactual circumstances (namely, those in which one's beliefs are true).

To appreciate the rationale for this distinction, suppose that the following holds:

(PEANUT) One ought not to give peanuts to a person if she has peanut allergies.

Lucy believes that Charlie has no allergies and gives him a peanut, which results in anaphylaxis. According to (PEANUT), given that Charlie is in fact allergic to peanuts, Lucy has done what she ought not to do. But, given what she believes, her action seems reasonable and (so) not criticisable. Though Lucy has violated the objective norm (PEANUT), she satisfies the following subjective norm:

(PEANUTS $T_{S} \quad$ One ought not to give peanuts to a person if one believes that she has peanut allergies.

More generally, whether an agent is to be evaluated positively or negative, as reasonable or otherwise, criticisable or not, is determined by whether she satisfies the subjective, not objective, norm.

\footnotetext{
${ }^{17}$ One might want to add that those beliefs must be rational or reasonable beliefs about the facts. For the remainder, I shall take this constraint as given.
} 
One might ask why we positively evaluate a subject doing what she subjectively should do, when, in doing so, she does what she objectively should not do. But the question seems to go a long way to answering itself - the subject is doing what, from her perspective, she should do, which is presumably all we can ask from finite creatures like ourselves. No doubt a fuller answer could be given but this suffices for present purposes.

In light of this, the orthodox Normativist might accept $\left(\mathrm{ACCORD}_{4}\right)$, so long as the 'may' in question is understood as subjective. The norm is derived from or generated in a familiar fashion by the objective (MAY) or its equivalents.

Armed with this framework, orthodox Normativists can say the following. While Bekki, in applying 'vixen' to a male cat which she believes to be a female fox, does what she objectively ought not to do, she is nonetheless doing what she subjectively may do. While Mike, in applying 'vixen' to a female fox which he believes to be a male cat, does what he objectively may do, he is nonetheless doing what he subjectively ought not to do. Thus, Mike's use of the term is criticisable or unreasonable in a way in which Bekki's is not. ${ }^{18}$ So, to accommodate the examples, the proponent of the orthodox reading needs only to distinguish the objective norm governing the use of 'vixen' and the subjective norm —-where the latter is explained in terms of the former. She does not need to introduce a species of normativity distinct from that which (MAY) and the like express.

This distinction between objective norms and subjective norms raises thorny issues, for example, concerning how to understand the verdicts the subjective norm delivers, especially where they seem to diverge from those the objective norm delivers. It is clearly beyond the scope of this paper to resolve these issues. My aim 
here is only to point out that, by appeal to a framework introduced and motivated independently of the issues which concern us, a proponent of the orthodox interpretation might be able, not only to accommodate (ACCORD 4 ), but to explain it. If this proves correct, it counts in favour of orthodoxy_-presumably one should not multiply norms beyond necessity.

\section{Conclusion}

In this paper, I considered an objection to the orthodox reading of the slogan 'Meaning is normative', according to which facts about correct application follow from facts about meaning. According to the objection, the slogan, so interpreted, conflates semantic correctness with factual correctness. One might respond to this by presenting the semantically correct use of an expression as distinct and potentially divergent from its correct application in assertion. This response, I argued, is unsuccessful, in part because the alternative understanding of the slogan proved elusive. In its place, I pointed to ways in which the advocate of the slogan might deal with the objection while holding on to the standard interpretation. Perhaps there are other problems facing the slogan, so interpreted, but for now, it seems, one can continue to maintain the status quo.

I have defended the view that the norms of meaning and the norms governing assertion are, so to speak, two sides of one coin. This suggests that one might make progress in the debates concerning the normativity of meaning, which often seem intractable, by considering the relationship between the fact that an expression bears a certain meaning and the fact that it can be used to perform a certain sort of speech act. Exploring this connection is the task for another occasion.

\footnotetext{
${ }^{18}$ Of course, the cases are underdescribed. If Mike, for example, is using the term as he does having
} 


\section{References}

Alston, W. 2000: Illocutionary Acts and Sentence Meaning. Ithaca: Cornell University Press.

Blackburn, S. 1984: The Individual Strikes Back. Synthese 58: 281-2.

Bloor, D. 1997: Wittgenstein: Rules and Institutions. London: Routledge.

Boghossian, P. 2008: Content and Justification. Oxford: Oxford University Press.

Brandom, R. 1994: Making it Explicit: Reasoning, Representing and Discursive Commitment. Cambridge, Massachusetts: Harvard University Press.

—. 2000: Articulating Reasons. Cambridge, Massachusetts: Harvard University Press.

Buleandra, A. 2008: Normativity and Correctness. Acta Analytica 23: 177-186.

Cavell, S. 2002: Must We Mean What We Say?, New ed. Cambridge: Cambridge University Press.

Gampel, E. 1997: The Normativity of Meaning. Philosophical Studies 86: 221-242.

Gibbard, A. 1994: Meaning and Normativity. Philosophical Issues 5: 95-115.

Ginsborg, H. 2011: Primitive Normativity and Skepticism about Rules. Journal of Philosophy 108: 227-254.

—. 2012: Meaning, Understanding, and Normativity. Aristotelian Society Supplementary Volume 86: 127-146.

Glendinning, S. 1998: On Being with Others: Heidegger, Derrida, Wittgenstein. London: Routledge.

Glock, H-J. 2005: The Normativity of Meaning Made Simple. PhilosophyScience-Scientific Philosophy, ed. A. Beckermann and C. Nimtz. Paderborn: Mentis. 
Glüer, K. and Wikforss, Å. 2009: The Normativity of Meaning and Content. Stanford Encyclopedia of Philosophy, ed. E. Zalta. URL:

http://plato.stanford.edu/entries/meaning-normativity/

Hacker, P. M. S. 2010: Meaning and Use. The Later Wittgenstein on Language, ed. D. Whiting. Basingstoke: Palgrave.

Haddock, A. 2012: Meaning, Justification, and "Primitive Normativity". Aristotelian Society Supplementary Volume 86: 147-174.

Hanfling, O. 2002: Wittgenstein and the Human Form of Life. London: Routledge.

Hattiangadi, A. 2006: Is Meaning Normative? Mind and Language 21: 220-40.

-. 2007: Oughts and Thoughts: Rule-Following and the Normativity of Content. Oxford: Oxford University Press.

Korsgaard, C.1996: The Sources of Normativity. Cambridge: Cambridge University Press.

Kripke, S. 1982: Wittgenstein on Rules and Private Language. Oxford: Blackwell.

Lance, M. and O’Leary-Hawthorne, J. 1997: The Grammar of Meaning. Cambridge: Cambridge University Press.

Luntley, M. 2003: Wittgenstein: Meaning and Judgement. Oxford: Blackwell.

McCulloch, G. 1995: The Mind and its World. London: Routledge.

McDowell, J. 1998: Mind, Value, and Reality. Cambridge, Massachusetts: Harvard University Press.

—. 2009: Having the World in View. Cambridge, Massachusetts: Harvard University Press.

McGinn, C. 1984: Wittgenstein on Meaning. Oxford: Blackwell.

Millar, A. 2004: Understanding People. Oxford: Oxford University Press.

performance. 
Miller, A. Forthcoming: Semantic Realism and the Argument from Motivational Internalism. What is Meaning?, ed. R. Schantz. New York: De Gruyter.

Moore, G. E. 1954: Wittgenstein's Lectures in 1930-1933. Mind 63: 289-316.

Morris, M. 1992: The Good and the True. Oxford: Oxford University Press.

Mulhall, S. 2003: Stanley Cavell's Vision of the Normativity of Language. Stanley Cavell, ed. R. Eldridge. Cambridge: Cambridge University Press.

Parfit, D. 2011: On What Matters: Volume One. Oxford: Oxford University Press.

Putnam, H. 1991: Representation and Reality. Cambridge, Massachusetts: MIT Press.

Railton, P. 2001: A Priori Rules: Wittgenstein on the Normativity of Logic. New Essays on the A Priori, ed. P. Boghossian and C. Peacocke. Oxford: Oxford University Press.

Schroeder, M. 2007: Slaves of the Passions. Oxford: Oxford University Press.

—. 2008: Expression for Expressivists. Philosophy and Phenomenological Research 76: 86-116.

Schroeder, S. 2006: Wittgenstein. London: Polity.

Segal, G. 2006: Truth and Meaning. The Oxford Handbook of Philosophy of Language, ed. E. Lepore and B. Smith. Oxford: Oxford University Press.

Sellars, W. 1962: Truth and "Correspondence”. Journal of Philosophy 59: 29-56.

Speak, J. 2009: The Normativity of Content and 'the Frege point'. European Journal of Philosophy 17: 405-415.

Stone, M. 1999: Wittgenstein on Deconstruction. The New Wittgenstein, ed. A. Crary and R. Read. London: Routledge.

Stroud, B. 2000: Meaning, Understanding and Practice. Oxford: Oxford University Press. 
Thornton, T. 1998: Wittgenstein on Language and Thought. Edinburgh: Edinburgh University Press.

Verheggen, C. 2011: Semantic Normativity and Naturalism. Logique et Analyse 216: $553-567$.

Waismann, F. and Wittgenstein, L. 2003: The Voices of Wittgenstein, ed. G. Baker. London: Routledge.

Way, J. 2009: Two Accounts of the Normativity of Rationality. Journal of Ethics and Social Philosophy December: 1-8.

Weiss, B. 2010: How to Understand Language. Durham: Acumen.

Whiting, D. 2009a: Is Meaning Fraught with Ought? Pacific Philosophical Quarterly 90: 535-55.

—. 2009b: On Epistemic Conceptions of Meaning: Use, Meaning and Normativity. European Journal of Philosophy 17: 416-434.

—. 2010: Particular and General: Wittgenstein, Linguistic Rules, and Context. The Later Wittgenstein on Language, ed. D. Whiting. Basingstoke: Palgrave.

—. 2013: Stick to the Facts: On the Norms of Assertion. Erkenntnis 78: 847-867.

Wikforss, Å. 2001: Semantic Normativity. Philosophical Studies 102: 203-26.

Williamson, T. 2000: Knowledge and its Limits. Oxford: Oxford University Press.

Wright, C. 2001: Rails to Infinity. Cambridge, Massachusetts: Harvard University Press. 